JOURNAL of

MAINE MEDICAL CENTER Journal of Maine Medical Center

\title{
Physician Shadowing: An Essential Practice in Fostering the Doctors of Tomorrow
}

Anna M. Martens

Tufts University School of Medicine

Et al.

Follow this and additional works at: https://knowledgeconnection.mainehealth.org/jmmc

Part of the Medical Education Commons

\section{Recommended Citation}

Martens, Anna M.; Linder, Jo; and Lewis, Janell (2021) "Physician Shadowing: An Essential Practice in Fostering the Doctors of Tomorrow," Journal of Maine Medical Center. Vol. $3:$ Iss. 1 , Article 7.

Available at: https://knowledgeconnection.mainehealth.org/jmmc/vol3/iss1/7 https://doi.org/10.46804/ 2641-2225.1062

The views and thoughts expressed in this manuscript belong solely to the author[s] and do not reflect the opinions of the Journal of Maine Medical Center or MaineHealth.

This Application of Best Practices is brought to you for free and open access by Maine Medical Center Department of Medical Education. It has been accepted for inclusion in the Journal of Maine Medical Center by an authorized editor of the MaineHealth Knowledge Connection. For more information, please contact Dina McKelvy mckeld1@mmc.org.

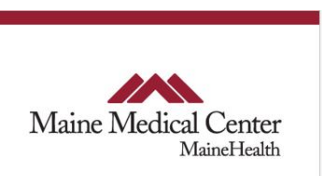




\section{Physician Shadowing: An Essential Practice in Fostering the Doctors of Tomorrow}

\section{Acknowledgements}

The authors would like to thank Dr. Robert L. Trowbridge for his insight, expertise and assistance with editing the manuscript.

\section{Authors}

Anna M. Martens, Jo Linder, and Janell Lewis 


\title{
Physician Shadowing: An Essential Practice in Fostering the Doctors of Tomorrow
}

\author{
Anna Martens, ${ }^{1}$ Jo Linder, MD, ${ }^{2}$ Janell Lewis, MS, CHES ${ }^{2}$ \\ ${ }^{1}$ Tufts University School of Medicine, Maine Track, Boston MA, ${ }^{2}$ Department of Medical Education, Maine Medical Center, \\ Portland ME.
}

\section{Problem Statement:}

Background:

Application/ Recommendation:

\begin{abstract}
Maine Medical Center (MMC) lacks a robust shadowing program, and there is inequity in shadowing opportunities for students from underrepresented minorities and economically disadvantaged backgrounds. Physician shadowing is essential for college students interested in going to medical school as it helps students make career decisions and strengthens their medical school applications. As we continue to expand our undergraduate programs in medical education and seek to grow our physician workforce, we need to provide students with equal opportunities to observe careers in medicine in order to foster interest and passion for the health field.
\end{abstract}

A robust body of literature demonstrates the powerful impact of shadowing on premedical students. Shadowing increases students' familiarity with physician responsibilities before committing to a career in medicine, intensifies their desire to attend medical school, and createshttps://www.zotero.org/googledocs/?MS4GBz an opportunity for them to develop career mentorship. Despite its importance, finding shadowing opportunities is often difficult for students, particularly for underrepresented minorities and students from economically disadvantaged backgrounds. Nationally and locally, the medical field struggles to recruit a diverse work force, which is imperative in addressing and improving health disparities. Part of the solution involves developing pipeline programs, such as shadowing experiences, to promote early exposure to the medical field and inspire students from all backgrounds to pursue a medical career. Around the country, shadowing programs are being developed to increase diversity in medical schools and the medical profession. Currently, MMC has a pipeline program, but it lacks resources to organize a robust shadowing program. With over 500 requests from students to shadow physicians at MMC over the past 2 years, there is a clear demand to improve the current shadowing program.

In examining other academic institutions' experience with implementing shadowing programs, and recognizing the demands of our community in Maine, we recommended improving the shadowing program for MMC. These recommendations included building on the current pipeline program, hiring a program coordinator to limit the administrative burden for physicians, recruiting physician mentors via an online database, providing resources to mentors on expectations and support, and using an online curriculum for students to make shadowing experiences more meaningful and longitudinal. By making shadowing part of the culture, increasing the number of shadowing positions, and streamlining the application process, we could create more equitable opportunities for all students to obtain shadowing experiences. This plan aligns strongly with MMC's Mission on Innovation, in which the institution has committed to investing in people, inspiring others, fostering creativity, and supporting lifelong learning and education.

Keywords: $\quad$ physician shadowing, medical school, medical students, premedical students, diversity
Becoming a doctor comes with many challenges. A student must first realize their potential in the field. Once committed, they face hard work,

Correspondence: Anna Martens

Tufts University School of Medicine, Maine Track

509 Forest Ave. 3rd floor. Portland, ME 04102

Anna.Martens@Tufts.edu determination, and sacrifice. In addition, physicians now experience high rates of burnout, excessive workloads, restricted autonomy, chronic workrelated stress, less time with patients, more bureaucracy, and lower compensation. ${ }^{1}$ For these reasons, it is imperative that those who choose 
to go into medicine have realistic perceptions of medicine as a career.

Physician shadowing has become an essential practice for medical school admissions as it allows students to make an informed career decision. At a small liberal arts college, $80 \%$ of premedical students had at least one shadowing experience ${ }^{2}$, and at an osteopathic medical school, $95.5 \%$ of students shadowed as a premedical student. ${ }^{3}$ As admissions to medical school become more competitive, shadowing experiences become crucial so that schools can ensure they are accepting students who understand the challenges that come with being a doctor. However, finding shadowing experiences is challenging, as the increased administrative burden can disincentivize physicians from offering these opportunities. ${ }^{4}$ Also, there are ethical considerations due to the potential impact on the physician-patient relationship. Importantly, students from underrepresented minorities and disadvantaged backgrounds have even less opportunities than their peers.

Underrepresented minorities and students from economically disadvantaged backgrounds may face additional barriers, such as a lack of role models in the medical field and access to opportunities for career exploration. The Association of American Medical Colleges estimates that by 2045, the United States will become majority-minority; yet, only $9 \%$ of current physicians identify as black or African American, Native American or Alaska Native, and Hispanic or Latino. ${ }^{5}$ Minority populations have less access to health care and a disproportionately high morbidity and mortality. ${ }^{6}$ Therefore, there is a major demand to prepare and train health care professionals who are culturally responsive and equipped to provide quality care in a multicultural society. Diversifying the health care workforce plays an essential part in addressing this demand. To recruit a diverse workforce, shadowing opportunities for underrepresented minorities and economically disadvantaged students must be established.

This review will explore the literature regarding the ethics of shadowing, the importance of shadowing for students, and how institutions have helped foster equitable shadowing opportunities for underrepresented minorities and economically disadvantaged students. Research questions addressed include: (1) What are the ethical https://knowledgeconnection.mainehealth.org/jmmc/vol3/iss 1/7 considerations surrounding shadowing? (2) Does shadowing impact the decision to pursue a career in medicine? (3) What are the best practices for creating equal shadowing opportunities for all students? This review will conclude with recommendations for MMC to incorporate shadowing into its workflow.

\section{METHODS}

Individuals involved in the guideline development group at MMC represent a multidisciplinary team, including a medical student, an assistant dean for students at Tufts University School of Medicine, a manager in the Health Career Pipeline Program, and the director of undergraduate medical education curriculum. The medical student conducted the literature review, and all members of the group were involved in understanding the current climate and infrastructure at MMC regarding shadowing, barriers around shadowing, and developing recommendations. Information gathered was used to inform recommendations by identifying the gaps in current programming and applying successful strategies developed by other institutions. These recommendations were developed for MMC and are generalizable to other academic institutions.

\section{THE ETHICS OF SHADOWING}

Ethical concerns have been raised with regards to shadowing. Some challenge that having a student involved in a visit impedes the physician's ability to carry out their ethical duties, which include maintaining patient trust, ensuring confidentially, preventing coercion to secure the patient's agreement to participate, and avoiding misrepresentation of the student's role. ${ }^{7}$ In the article "Shining a Light on Shadowing," Kitsis notes that "Physicians, as fiduciaries, must always act in the patients' best interest, and subordinate their own self-interests and the interests of others." He raises the issue of the difference between medical students shadowing, a practice that is generally not seen as ethically problematic, and college students shadowing. He argues that medical students shadowing physicians may ultimately benefit society by providing a valuable educational experience in which students learn medicine. Conversely, college students have not committed to a career in medicine and are using the experience to make a career decision and help gain admission to medical school. Additionally college students have not passed the rigorous admission process of medical school and are not held to as high of standards 
as medical students who are expected to behave in a professional manner upon admission. ${ }^{7}$ Kitsis concludes that "Any possible benefit of physician shadowing by college students in facilitating this decision is trumped by the need to uphold the sanctity of the patient-physician relationship.""

On the other hand, in a qualitative study about patients' perceptions of college students shadowing physicians, no patient thought that the student affected the visit in a negative way or that the student impacted their ability to maintain a trusting relationship. The majority of patients had no concerns about confidentiality. ${ }^{8}$ These findings are consistent with a deep body of literature regarding the role of trainees in clinical care and patients' strong acceptance of the practice.

\section{THE IMPORTANCE OF SHADOWING}

Students who participate in shadowing programs have reported increased familiarity with physician responsibilities, while also gaining exposure to other health care careers. ${ }^{9,10}$ Medical schools highly value shadowing experiences. According to the 2016 Group on Student Affairs Committee on Admissions Survey, conducted by the Association of American Medical Colleges, "73\% of medical schools surveyed highly recommend or require applicants to have had experience in which they can observe and learn about clinical practices" and " $87 \%$ of respondents reported that applicants without clinical experience may be disadvantaged in the application process." 11 Most schools noted that they would accept alternate activities (eg, emergency medical technician, scribe, certified nursing assistant) if applicants were unable to secure shadowing experience.

Shadowing is also an opportunity for early exposure and motivation. The large majority of medical students endorse that shadowing experiences before medical school increased their desire to attend medical school.,12,13,14 Shadowing experiences can also be gateways for students to develop career mentors and obtain a letter of recommendation for medical school. ${ }^{3,10,15}$ This aspect is crucial, especially for those students from disadvantaged backgrounds who may have less connections to the medical field. 2,16

New, innovative techniques to enhance shadowing experiences are being developed. The University of Kentucky developed a course, Doctoring
Undercover, to expand on the traditional approach of shadowing. Through this course, students learn about medical culture in the context of shadowing with an accompanying online guide. ${ }^{17,18}$ In a qualitative analysis, students' gained new perspectives on medical science disciplines; increased awareness of the psychological, social, and cultural aspects of medicine; and strategies for personal reflection on medical practice. ${ }^{18}$

Shadowing can also benefit the physician being shadowed. An undergraduate shadowing program in a pediatric clinic used resident physicians as primary supervisors. The program found that $72 \%$ of surveyed residents agreed that they enjoyed having the undergraduates in the clinic, and $45 \%$ agreed that the undergraduates improved their workflow in the clinic. The survey showed that shadowing can be a positive experience for all participants, and that fostering premedical student interest in pediatrics and primary care can possibly lead to more physician commitment to these fields. ${ }^{19}$

\section{CREATING EQUITABLE OPPORTUNITIES}

As Julie Freischlag, Dean of Wake Forest School of Medicine, states: "The decision to not allow shadowing would do harm in opening the door to many who would not have considered being a physician or a surgeon. Many women and minorities especially need to see themselves as physicians or surgeons. It is imperative to give these students such an experience so that the physicians of the future will be diverse, compassionate, and caring. I know, without a shadow of a doubt, that the patients of the future will thank the patients of today who were shadowed." 20

Underrepresented undergraduate freshmen who intend to enter medical school are $50 \%$ less likely to apply to medical school by the time they are seniors than their counterparts. ${ }^{21}$ This percentage has been linked to lacking quality role models and exposure to health care careers. Additionally, premedical students from lower income families have less shadowing experiences than those from higher income families. ${ }^{2}$ An additional barrier for many students is that shadowing opportunities are unpaid volunteer opportunities, a major challenge for students who rely on paid employment. These students may not have the time and luxury to seize unpaid opportunities, particularly if travel and housing are also required. To address these 
disparities, numerous academic medical centers have developed shadowing programs specifically for underrepresented minorities and economically disadvantaged students.

The University of Colorado developed a year-long program for underrepresented minority students interested in health care careers. Students were paired with a hospitalist for mentoring and job shadowing. All students "strongly agreed" that participating in the program expanded their perceptions of what they might accomplish and increased their confidence in their ability to enter a health care profession. In a 2-year follow up, 95\% of these students remained committed to a career in health care. ${ }^{14}$

At the University of Connecticut School of Medicine and Dentistry, a pipeline program was developed to recruit a more diverse pool of students into health care and science fields. To participate in the pipeline's more advanced programs, applicants must meet certain criteria, such as maintaining a "B" average or higher and having multiple letters of recommendation. Over the past 15 years, approximately half of incoming medical and dental classes have participated in one of the pipeline programs. More than 560 participants moved on to attend medical school, dental school, or graduate school. ${ }^{22}$ Implementing formal shadowing programs geared towards underrepresented minorities and economically disadvantaged students may help increase diversity in medical schools and the medical profession.

Shadowing may also empower students through early exposure and help overcome traditional gender biases. At the University College London, the "Surgical Shadowing Scheme" assessed how recruiting surgeons to engage in shadowing would affect undergraduate attitudes to surgical careers. The study found that traditionally male-dominated surgical subspecialties recruited a high proportion of female students. They found that even a single high-quality surgical exposure is sufficient to increase the desire of undergraduates to pursue a surgical career. ${ }^{4}$

\section{RECOMMENDATIONS FOR MAINE MEDICAL CENTER}

Shadowing provides an opportunity to develop and recruit a young, diverse population of future health care professionals, which could help to address the https://knowledgeconnection.mainehealth.org/jmmc/vol3/iss 1/7 DOI: $10.46804 / 2641-2225.1062$ current shortage of physicians in Maine. Currently, MMC is lacking a robust shadowing program. As a result, students who shadow physicians often have personal connections to clinicians, resulting in inequitable opportunities for those who do not have such connections. As Maine's largest medical center, MMC has a responsibility to provide equal opportunities to all students interested in shadowing. This need is clear-in the past 2 years, MMC's Health Career Pipeline Program had over 500 requests from students to shadow. Incorporating a standardized shadowing experience at MMC that is accessible to all Maine students aligns strongly with MMC's Mission on Innovation in which the institution has committed to investing in people, inspiring others, fostering creativity, and supporting lifelong learning and education. ${ }^{23}$ As the strategic plan states, "To succeed, we must deliver breakthrough strategies that position our health system for success." 24 There is likely no better way to position our health system for success than to provide experiences in the health field to young, motivated students who are deeply rooted in their communities. As we continue to develop undergraduate programs in medical education, we must also provide all students of Maine with opportunities to strengthen their medical experience. In turn, these efforts would likely increase the number, diversity, and competitiveness of applications to the Tufts University School of Medicine Maine Track. 3,10,14,15

In this opportunity to develop and expand on shadowing experiences for college students, it is important to hold a patient-centered approach at the forefront. Ultimately, having diverse and prepared medical students will improve patient care and benefit society, which we must keep in mind to ensure that shadowing opportunities do not jeopardize the trusted patient-physician relationship.

Currently, through the Department of Medical Education, MMC's Health Career Pipeline Program includes opportunities for students ranging from primary school to college. While these opportunities include job shadowing, the current process is limited. Students who are interested in shadowing through the Health Career Pipeline Program work with a manager who obtains all necessary paperwork and sets the student up with a physician. Currently, there is no contact list for designated physicians who are willing to have a student shadow them, so this process is time consuming. Additionally, there is 
no shadowing policy or curriculum for students and physicians to follow. If the student wants to shadow a surgeon, there are additional steps that must be taken. Unfortunately, there is no follow up for these students due to limited administrative capacity.

Incorporating a shadowing program into MMC will come with challenges. While MMC providers are willing to take on a student, they often have limited time. There are also concerns about the possible impact on productivity, burdensome onboarding process, and lack of curriculum for providers to follow. It also takes time for providers to work out processes for incorporating students into the clinical workflow. There would also be potential for perceived competition for learning opportunities when adding an additional junior learner to the mix of fellows, residents, and/or medical students on some teaching services. Additional barriers include the need to overcome the current structure that results in inequities so that all students have equal access to shadowing experiences.

Despite these barriers, developing a more rigorous and equitable shadowing program is possible. This effort will require buy-in from department chairs and hospital leadership to support providers in this process. Hiring a designated shadowing coordinator would be essential for recruiting physicians and streamlining the application and on-boarding process. Incorporating shadowing into the routine workflow and limiting administrative burden will help reduce the impact on productivity for physicians. Using an online curriculum will help to make these experiences more meaningful and longitudinal. Additionally, the program could expand to coordinate shadowing experiences in the MaineHealth system, including office practices and community hospitals. This expansion would increase access for students across the state and relieve MMC from having to provide most shadowing experiences for students across Maine. Table 1 describes more specific recommendations.

Shadowing is an essential step in the process of becoming a doctor. It allows students to realize their potential, gain exposure to different aspects of medicine, and develop career mentors. MMC has an opportunity to foster meaningful shadowing experiences for young and talented students across Maine. In providing early exposure to various medical fields, and helping all students realize their goals of becoming physicians, shadowing can help to foster a diverse pool of students from Maine who pursue careers in medicine.

Table 1. Recommendations for Implementing a Robust, Evidence-Based Shadowing Program at MaineHealth Sites. $^{1}$

\begin{tabular}{|c|c|}
\hline Recommendation & Description of recommendation* \\
\hline Hire a coordinator & $\begin{array}{l}\text { - The coordinator facilitates shadowing processes, including dispersing and } \\
\text { obtaining applications, connecting students to mentors, streamlining regula- } \\
\text { tory requirements and guidelines, and educating community partners on the } \\
\text { shadowing program. }\end{array}$ \\
\hline $\begin{array}{l}\text { Develop a process } \\
\text { for recruiting and } \\
\text { educating mentors }\end{array}$ & $\begin{array}{l}\text { - Physicians contacted annually via email to invite them to volunteer as men- } \\
\text { tors. Interested physicians upload basic information about their practices, } \\
\text { including their weekly schedule (if possible), to an online database. Coordi- } \\
\text { nators pair students one-on-one with mentors. } \\
\text { - Educate mentors via an online tutorial that explains expectations of students, } \\
\text { ongoing curriculum, and mentoring advice. }\end{array}$ \\
\hline $\begin{array}{l}\text { Standardize the ap- } \\
\text { plication process }\end{array}$ & $\begin{array}{l}\text { - } \quad \text { College students older than } 16 \text { years are eligible to apply. } \\
\text { - } \quad \text { Short answer responses to prompts that explore their interest in shadowing. }{ }^{7} \\
\text { - } \quad \text { Applicants are accepted based on their suitability for the program, seniority, } \\
\text { and previous participation, as well as the availability of physician mentors } \\
\text { and other logistical factors. }\end{array}$ \\
\hline
\end{tabular}




\begin{tabular}{|c|c|}
\hline $\begin{array}{l}\text { Standardize regu- } \\
\text { latory requirements } \\
\text { and guidelines }\end{array}$ & $\begin{array}{l}\text { - Students attend an orientation to learn about professionalism, clinic etiquette, } \\
\text { infection control, and HIPAA. They also receive a hospital badge with photo } \\
\text { identification. Additionally, they must complete the immunizations and other } \\
\text { health requirements. Orientation to a specific clinical site is also conducted at } \\
\text { this time. } \\
\text { - Guidelines provided to both students and physicians outlining the goals of } \\
\text { shadowing, including learning objectives, student and physician responsibili- } \\
\text { ties, and code of conduct forms. }{ }^{25,26}\end{array}$ \\
\hline $\begin{array}{l}\text { Standardize shadow- } \\
\text { ing experience and } \\
\text { expectations }\end{array}$ & $\begin{array}{l}\text { - Continuous relationship between student and mentor. Experiences tailored } \\
\text { for students depending on educational level and schedule. } \\
\text { - Student must attend a minimum number of shadowing sessions within a } \\
\text { certain number of weeks. } \\
\text { - Shadowing sessions may involve observing the physician in outpatient clin- } \\
\text { ics, in the operating room, or during inpatient rounds; accompanying the phy- } \\
\text { sician to departmental grand rounds; or holding mentoring meetings outside } \\
\text { of the clinical setting. } \\
\text { - Students should also be provided opportunities to work with medical students } \\
\text { and residents. }\end{array}$ \\
\hline $\begin{array}{l}\text { Develop a longitudi- } \\
\text { nal curriculum }\end{array}$ & $\begin{array}{l}\text { - Throughout their experience, students are required to view the online mod- } \\
\text { ules (Prepare/Observe/Reflect) by the University of Kentucky and submit } \\
\text { their reflections. }{ }^{17}\end{array}$ \\
\hline $\begin{array}{l}\text { Disseminate appli- } \\
\text { cation to college } \\
\text { students }\end{array}$ & $\begin{array}{l}\text { - College premedical advisors should be made aware of this program and } \\
\text { given access to the application. } \\
\text { - Application should be available online. }\end{array}$ \\
\hline $\begin{array}{l}\text { Pair with Maine- } \\
\text { Health office practic- } \\
\text { es and community } \\
\text { hospitals }\end{array}$ & $\begin{array}{l}\text { - The shadowing coordinator would be responsible for outreach to other } \\
\text { MaineHealth physicians and practices in order to coordinate shadowing ex- } \\
\text { periences in the MaineHealth system. }\end{array}$ \\
\hline
\end{tabular}

${ }^{*}$ Considerations in formulating this plan included building on the existing infrastructure and discussion among stakeholders in developing a sustainable program.

${ }^{1}$ Adapted from Kitsis et al.

\section{References}

1. Wallace JE, Lemaire JB, Ghali WA. Physician wellness: a missing quality indicator. Lancet. 2009;374(9702):1714-1721 doi:10.1016/S0140-6736(09)61424-0.

2. O'Connell VA, Gupta J. The premedical student: training and practice expectations. Med Educ Online. 2006;11(1):4590. doi:10.3402/meo.v11i.4590.

3. Langenau E, Frank SB, Calardo SJ, Roberts MB. Survey of osteopathic medical students regarding physician shadowing experiences before and during medical school training. $J$ Med Educ Curric Dev. 2019;6:2382120519852046. doi:10.1177/2382120519852046.

4. Bartlett RD, Momin SM, Azam S, Rotimi O, Quick TJ. Development of a "Surgical Shadowing Scheme" to improve undergraduate experiences of surgery. Adv Med Educ Pract. 2019;10:619-626. doi:10.2147/AMEP.S205054.

5. Association of American Medical Colleges. Creating and sustaining a diverse and culturally responsive workforce. Accessed June 4, 2020. https://www.aamc.org/news-insights/ diversity-issues.

6. Centers for Disease Control and Prevention. Surveillance of health status in minority communities --- racial and ethnic approaches to community health across the U.S. (REACH U.S.) risk factor survey, United States, 2009. Accessed February 10, 2020. https:// www.cdc.gov/mmwr/preview/mmwrhtml/ss6006a1.htm.

7. Kitsis EA. Shining a Light on Shadowing. JAMA. 2011;305(10):1029-1030. doi:10.1001/jama.2011.267.

8. Bing-You RG, Hayes VM, Skolfield JL. Physician shadowing by college students: what do patients think? BMC Res Notes. 2014;7:146. doi:10.1186/1756-0500-7-146. 


\section{Martens et al.: Physician Shadowing}

9. Teitz CC. Shadowing Physicians. JAMA. 2011;305(23):24142416. doi:10.1001/jama.2011.787.

10. Wang JY, Lin H, Lewis PY, Fetterman DM, Gesundheit N. Is a career in medicine the right choice? The impact of a physician shadowing program on undergraduate premedical students. Acad Med. 2015;90(5):629-633. doi:10.1097/ ACM.0000000000000615.

11. Group on Student Affairs, Committee on Admissions. Clinical Experiences Survey Summary; Executive Summary of GSA Committee on Admissions Survey Regarding Clinical Experiences. Association of American Medical Colleges; 2016. https://www.aamc.org/system/files/c/2/474256-gsa-coa-clinicalshadowing-experience-executive-summary.pdf

12. Larson J, Atkins RM, Tucker P, Monson A, Corpening B, Baker S. The University of Oklahoma College of Medicine summer medical program for high school students. J Okla State Med Assoc. 2011;104(6):255-259. https://pubmed.ncbi.nlm.nih. gov/21888040.

13. Hunter N, Shah A, Bollina P, Bollina H. Improving medical work experience for students. Clin Teach. 2010;7(4):284-287. doi:10.1111/j.1743-498X.2010.00405.x.

14. Briskey, Michael, Ayyash, Ali, Chang, Angela, Mulcahey, Mary K. The effect of DUCOM's Mini-Medical School Summer Camp on students' interests in medicine. J Natl Med Assoc. 2017;109(2):107-114. doi:10.1016/j.jnma.2017.01.002.

15. Medical Career Exploration Program. Brigham and Women's Hospital. Accessed February 14, 2020. https://www. brighamandwomens.org/about-bwh/volunteer/medical-careerexploration-program-overview.

16. Cervantes, Lilia, Chu, Eugene, Nogar, Carmella, et al. A hospitalist mentoring program to sustain interest in healthcare careers in under-represented minority undergraduates. $J$ Hosp Med. 2014;9(9):586-589. doi:10.1002/jhm.2218.
17. Shadowing: An active approach to healthcare exploration. Shadowing.healthcare. Accessed February 17, 2020. http://www. shadowing.healthcare.

18. Clark CD. Doctoring Undercover: updating the educational tradition of shadowing. Med Educ Online. 2016;22(1):1265848. doi:10.1080/10872981.2017.1265848.

19. Thang C, Barnette NM, Patel KS, et al. Association of shadowing program for undergraduate premedical students with improvements in understanding medical education and training. Cureus. 2019;11(12):e6396. doi:10.7759/cureus.6396.

20. Freischlag JA. Shadowing Physicians. JAMA. 2011;305(23):24142416. doi:10.1001/jama.2011.789.

21. Barr DA, Gonzalez ME, Wanat SF. The leaky pipeline: factors associated with early decline in interest in premedical studies among underrepresented minority undergraduate students. Acad Med. 2008;83(5):503-511. doi:10.1097/ ACM.0b013e31816bda16.

22. UConn health honored for diversifying STEM workforce. UConn Today. Accessed February 14, 2020. https://today.uconn. edu/school-stories/uconn-health-awarded-diversifying-stemworkforce.

23. Our Values. MaineHealth. Accessed February 16, 2020. https:// mainehealth.org/about/our-values.

24. Strategic Plan. MaineHealth. Accessed February 16, 2020. https:// mainehealth.org/about/strategic-plan.

25. Kitsis EA, Goldsammler M. Physician shadowing: a review of the literature and proposal for guidelines. Acad Med. 2013;88(1):102110. doi:10.1097/ACM.0b013e318277d5b2.

26. Guidelines for clinical shadowing experiences or pre-medical students. Association of American Medical Colleges. Accessed February 16, 2020 https:/www.aamc.org/system/files/ c/2/356316-shadowingguidelines2013.pdf. 